\title{
Isolated Tuberculosis of The Sternum Detected with GeneXpert: A Case in an Adult Girl
}

\author{
H Harmouchi ${ }^{1 *}$, M Lakranbi ${ }^{1,2}$, FZ Ammor ${ }^{1}$, L Belliraj ${ }^{1}$, I Issoufou ${ }^{1}$, Y Ouadnouni ${ }^{1,2}$ and M Smahi ${ }^{1}$ \\ ${ }^{1}$ Department of Thoracic Surgery CHU Hassan II of Fez-Morocco \\ ${ }^{2}$ Faculty of Medicine and Pharmacy, Sidi Mohamed Ben Abdellah University, Fez-Morocco
}

Received: 㭗: July 14, 2018; Published: 觜 July 30, 2018

*Corresponding author: H Harmouchi Hicham, Thoracic surgery department, CHU Hassan II of Fez-Morocco.

\begin{abstract}
Sternal tuberculosis is a form of osteoarticular tuberculosis. It remains a rare localization, whose diagnosis is based on bacteriological and anatomopathological samples. The treatment is medical and surgical, and the prognosis is better with the antibacillary treatment. We report a case of sternal tuberculosis in an 18-year-old girl with no pathological history who presented with a parasternal right swelling and whose Bacteriological samples was favorable for tuberculosis according to GeneXpert test and the histological analysis revealed a granulomatous lesion without caseous necrosis.
\end{abstract}

Keywords: Tuberculosis; Sternum; Surgery

\section{Case Report}

She is Miss S.A, aged 18, with no notable pathological history, including no tuberculosis or concept of tuberculous contusion, which has had a parasternal right swelling for a month. The examination of the swelling found a parasternal right mass just below the clavicle opposite the first intercostal space, painful on palpation, with redness, without cutaneous fistulization. An initial chest x-ray was requested returning without abnormality, in particular no lysis opposite, or associated parenchymatous involvement, with an infectious assessment negative made of a blood cell parameters and C- reactive protein, A thoracic computed tomography was performed objectifying an osteolytic lesion with intraosseous sequestration at the right super-lateral part of the sternum (Figure 1), associated with infiltration of the soft tissues and two abscesses, the first at right intercostal muscle level, and the second in the anterior parietal area (Figure 2). Flattening of the swelling was performed in the patient, with bacteriological and histological samples of the abscess. The direct examination and the culture of the pus came back negative. However, the molecular study of the collection by GeneXpert objectified a tuberculosis. The anatomopathological study revealed a granulomatous lesion, but without caseous necrosis. The patient was put on antibacillary treatment with good clinical progress.

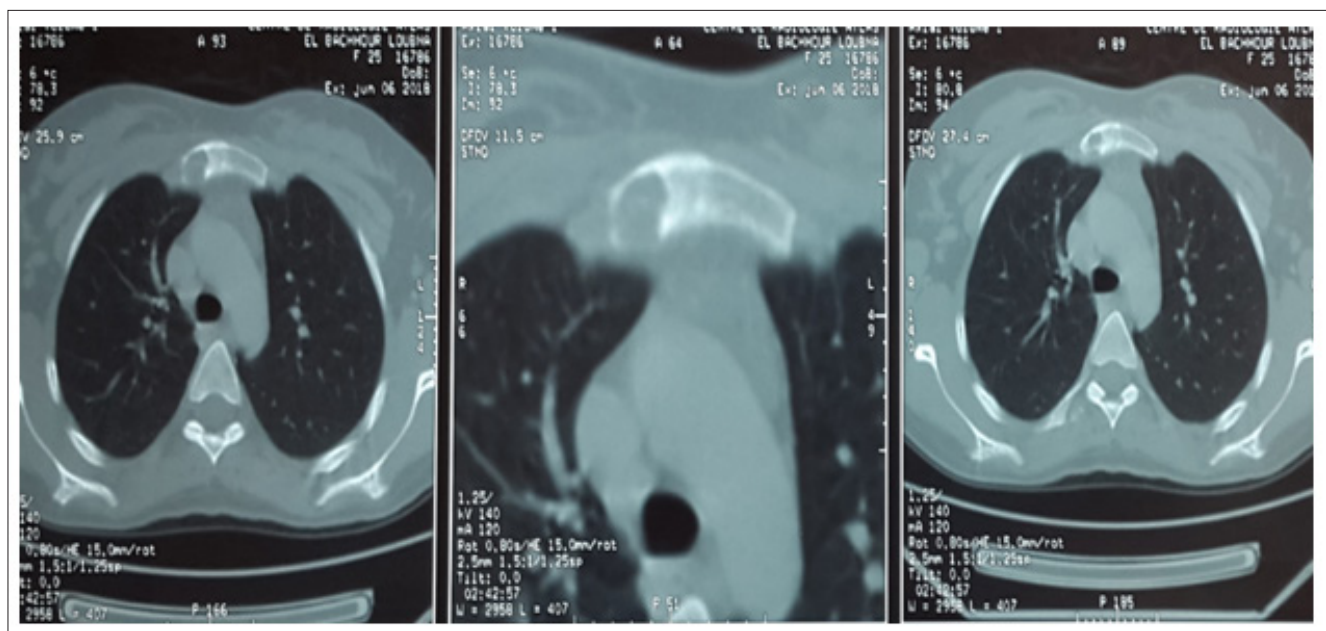

Figure 1: Osteolytic involvement with intraosseous sequestration at the right superior-lateral part of the sternum. 


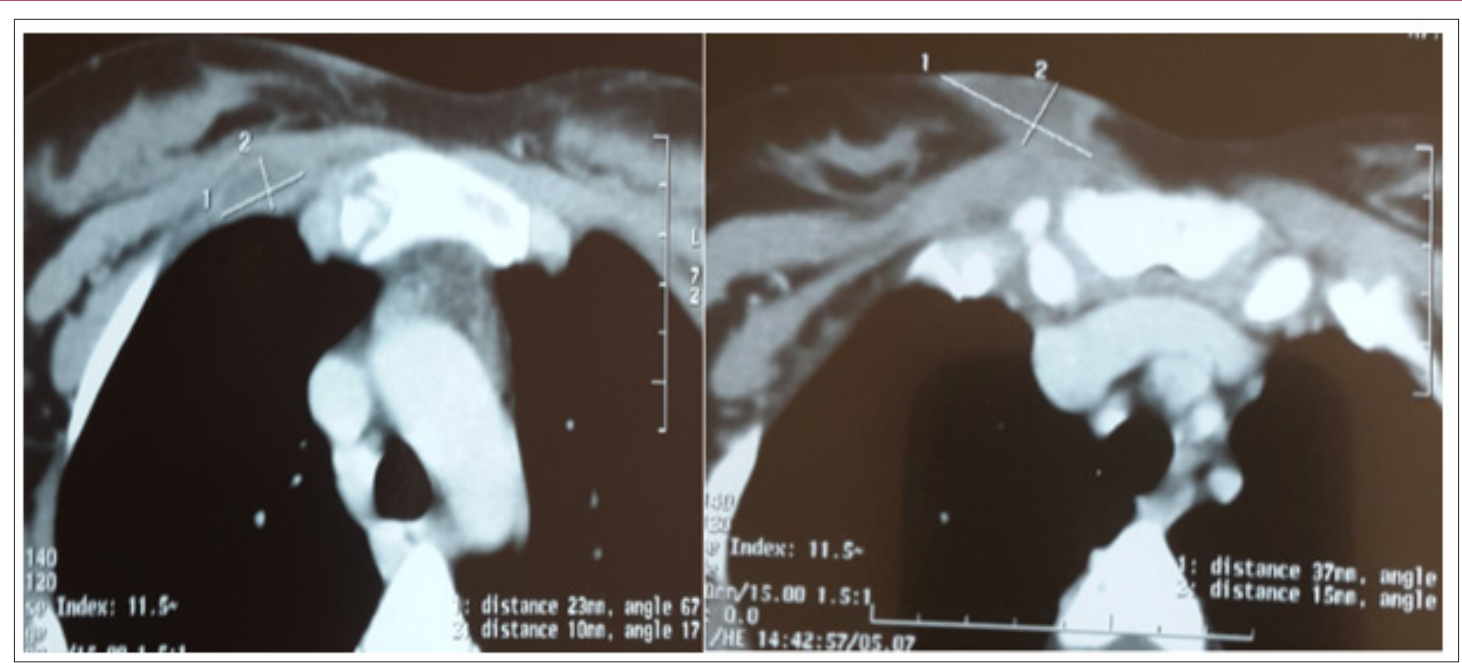

Figure 2: Presence of two parietal abscesses, one at the level of the right intercostal muscle, and the second at the anterior parietal level.

\section{Discussion}

Tuberculosis is an infectious disease that is still rife in Morocco in endemic form. It is most often due to Mycobacterium Tuberculosis. Osteoarticular tuberculosis mainly affects the spine, hip or knee [1]. Localization at the chest wall represents less than $5 \%$ of osteoarticular tuberculosis, and whose sternal involvement remains more rare, and estimated at 1 to $2 \%$ [2-3]. Dissemination occurs either by a hematogenous or lymphatic pathway or by direct contiguity from mediastinal adenopathy's or pleural empyema [45]. The clinical aspects are varied, especially in the absence of signs of tuberculous impregnation, or other associated pulmonary or extra-pulmonary sites suggestive of tuberculosis [6].

These aspects can range from a simple swelling of the soft tissues, related to a cold abscess, to a spontaneous sternal fracture [7]. This makes the diagnosis difficult, and is a source of delayed care. As a result, ultrasound-guided biopsy or flattening of the abscess is indicated in the majority of cases to establish a histological and or bacteriological diagnosis [6-8]. In our case, the diagnosis was reported by the GeneXpert on the collection of pus, however the histologic sample showed only a granulomatous lesion without cystic necrosis. Thoracic CT can contribute to the diagnosis by showing a sternal lysis, intraosseous sequestration, or associated wall abscess, but also to identify underlying pulmonary involvement and to guide possible biopsy or drainage [2-5]. The treatment of sternal tuberculosis remains medico-surgical. The prognosis is good after antibacillary treatment [9]. Medical treatment is instituted as soon as the diagnosis is made. it is based on the combination of several antibacillaries, the most used of which are rifampicin, isoniazid, pyrazinamide and ethambutol. They are associated for 2 to 4 months and the relay is provided by rifampicin and isoniazid until the seventh or tenth month depending on the general condition of the patient and the degree of extension of the lesions. Surgical treatment may be indicated to excise cold abscess developed in the soft tissues [10].

\section{Conclusion}

Sternal tuberculosis remains a rare pathology of difficult diagnosis, which relies mainly on bacteriological and histological samples. the treatment is medical by the antibacillary and surgical treatment by the flattening of the abscess and sometimes drainage.

\section{References}

1. T. Kilani, MS. Boudaya, H. Zribi, S. Ouerghi, A. Marghli, et al. (2014) La chirurgie dans la tuberculose thoracique Surgery for thoracic tuberculosis. Revue de Pneumologie clinique 71(2-3): 140-158.

2. Abida M, Ben Amar M, Abdenadher M, Haj Kacem A, MzaliR, et al. (2010) Abcès de la paroi thoracique et abdominale isolé : une forme exceptionnelle de tuberculose. Rev Mal Respir 27(1): 72-75.

3. Bouslama K, Bakir L, Ben M'rad S, Aloulou R, Hendaoui L, et al. (1998) Tuberculose de la paroi thoracique: apropos d'un cas et revue de la littérature. Med Mal Infect 28: 666-667.

4. Mahouachi R, Zendah I, Taktak S, Chtourou A, Ben Chaabane R, et al. (2006) Tuberculose de la paroi thoracique. Rev Pneumol Clin 62: 56-58.

5. Chermiti Ben Abdallah F, Boudaya MS, Chtourou A, Taktak S, Mahouachi $\mathrm{R}$, et al. (2013) Tuberculose sternale avec fractures pontanée du sternum. Rev Pneumol Clin 69(2): 89-92.

6. El Kharras, M. Jidal, L. Achemlal, M. Atmane, S. Chaouir, et al. (2004) Benameur Tuberculose sternale isolée. Deux observations. Presse Med 33(22): 1579-1581.

7. Watts RA, Paice EW, White AG (1987) Spontaneous fracture of the sternum and sternal tuberculosis. Thorax 42(12): 984-985.

8. Shah J, Patkar D, Parikh B, Parmar H, Varma R, et al. (2000) Tuberculosis of the sternum and clavicle: imaging findings in 15 patients. Skeletal Radiol 29(8): 447-453.

9. E.M. Aghoutane, R. Fezzazi (2011) Tuberculose sternale isolée chez l'enfant: à propos d'un cas. Isolated tuberculosis of the sternum in children: Case report. Revue de Pneumologie clinique 67(5): 322-324.

10. Rachid K, Chkoura M, Moudene A (2001) Localisations rares de la tuberculose osseuse. À propos de trois cas. Rev Chir ortho 87(2): 176179. 


\section{ISSN: 2574-1241}

DOI: 10.26717/BJSTR.2018.07.001494

H Harmouchi Hicham. Biomed J Sci \& Tech Res

(c) (i) This work is licensed under Creative

Submission Link: https://biomedres.us/submit-manuscript.php

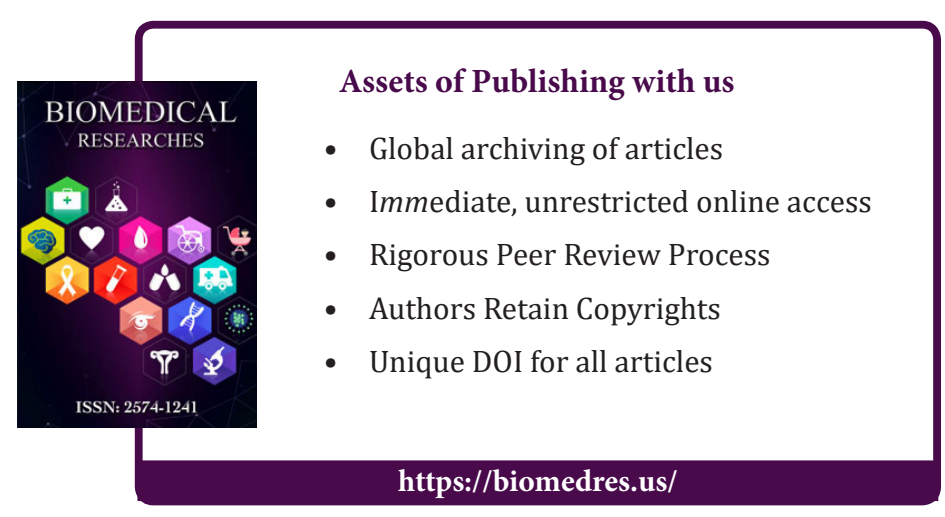

